\title{
Darker Shades of Joy: The Role of Negative Emotion in Rich Product Experiences Steven Fokkinga, Pieter Desmet
}

\section{Introduction}

Imagine you are moving to a new city. What emotions would you experience? You might feel sad about leaving your family and friends. At the same time, you might also feel hopeful about the opportunities awaiting your new life, joy over the prospect of exploring your new city and meeting new people, and anxiety about not knowing anyone yet. The combination of all these different emotions makes the transition a complex but rich experience that you will long remember.

Several authors in the field of user experience and interaction design have expressed the opinion that product experiences should mirror the richness of these kinds of real-life experiences. Hassenzahl recently suggested that product experiences should be "worthwhile" or "valuable" to avoid the pitfall of shallow amusement in experience design. ${ }^{1}$ Likewise, Arrasvuori et al. investigated the possibilities of translating the wide range of emotions in video games to create more engaging consumer products. ${ }^{2}$ With their concept of "design noir," Dunne and Raby even proposed a new genre of design to complement the prevailing "Hollywood" tradition of products that offer a limited experience. ${ }^{3}$ They proposed that design noir "could enrich and expand our experience of everyday life rather than closing it down." ${ }^{\prime 4}$ Although working in different research traditions, these authors share the underlying view that engaging product experiences should go beyond simplified assumptions about people, acknowledging the complexity of their desires and behavior.

This view is illustrated by a number of interesting design examples. Dunne and Raby discussed the "Life counter" by Ippei Matsumoto (see Figure 1). ${ }^{5}$ This digital clock-like product lets users decide how many years they would like to live and then starts counting back. Once activated, the different sides of the product display the number of years, days, hours, and seconds they have left, respectively, which forces the user to choose whether to see the years of their lifetime dragging on, or the seconds flashing before their eyes. Another example is Alice Wang's "The Tyrant" (see Figure 2), as described by Hassenzahl. ${ }^{6}$ This alarm clock 

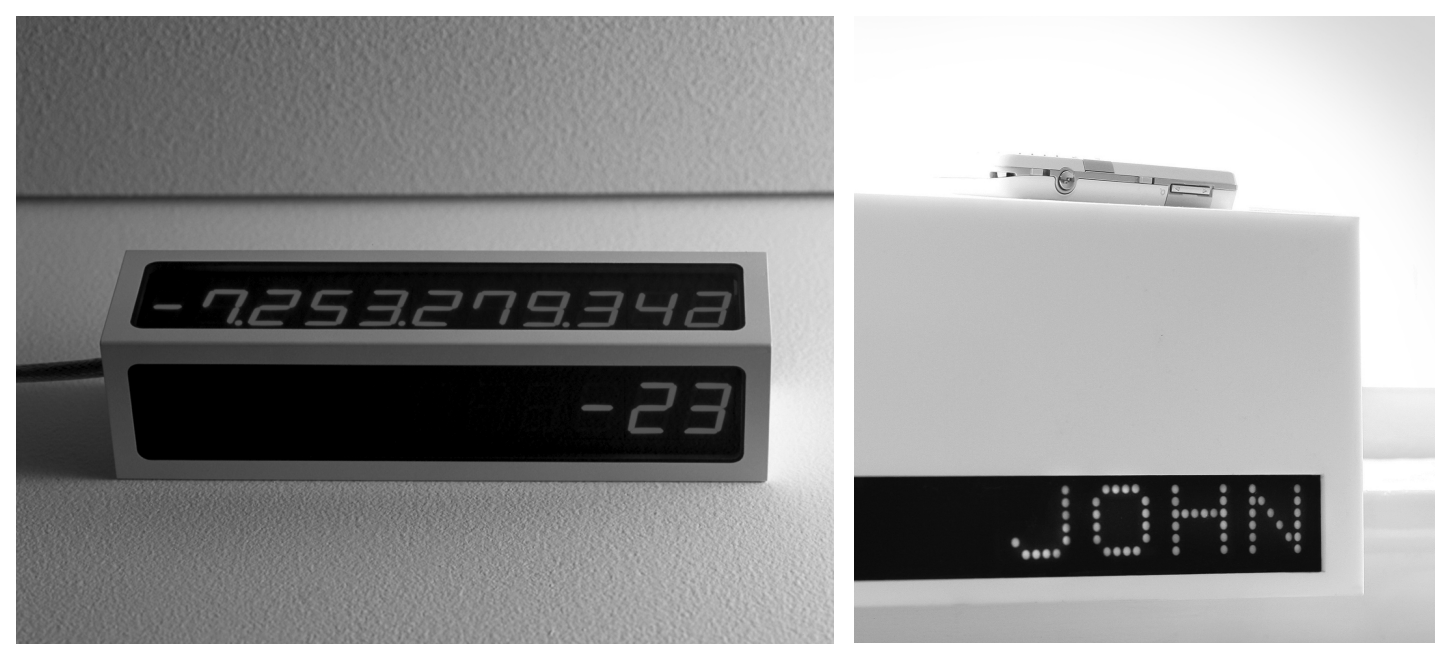

Figure 1 (left)

Life Counter. Photo: Hidetoyo Sasaki.

Figure 2 (right)

The Tyrant.
7 William W. Gaver et al., "The Drift Table: Designing for Ludic Engagement," in $\mathrm{CHI}$ '04 Extended Abstracts on Human Factors in Computing Systems (New York: ACM, 2004), 885-900.

8 Hassenzahl, Experience Design, 29.

9 Gaver et al., "The Drift Table," 897-98. wakes the user, not by sounding an alarm, but by calling random people from the user's address book every three minutes after the wake-up time. The daunting prospect of bothering random acquaintances is expected to motivate users to get out of bed. Gaver et al. designed "The Drift Table" (see Figure 3), a coffee table with a small hole in the middle that reveals a satellite view of England's countryside. ${ }^{7}$ This view floats in a certain direction, corresponding to the arrangement of physical objects on the table. Thus, as more weight is put on a certain side of the table, the image shifts more quickly in that direction. The idea is that the interaction with a product that lacks both clear functionality and direct controls enables the user to have a more open and exploratory experience.

These products clearly illustrate the aim to avoid the pitfall of shallow amusement mentioned by Hassenzahl. ${ }^{8}$ We believe they do so because they evoke a larger spectrum of emotions than more conventional products. In particular, besides evoking positive emotions, they also elicit several negative emotions. For instance, the "Life Counter" has a pleasantly sinister or morbid quality, provoking emotions of mild horror, anxiety, and sadness. "The Tyrant" clearly tries to evoke shame in users for bothering random acquaintances with their problems in getting up. Furthermore, the anticipatory fear that the product will actually do this is a strong incentive for users to get up. Lastly, "The Drift Table" was purposefully designed to conceal a clear intention of use, and to restrict users in the way they could control the table. Both these design decisions can elicit frustration and annoyance in users, as the researchers also encountered with testers of the device. ${ }^{9}$

Regarding negative emotions as a key element of rich product experiences, instead of an unwanted side effect of product interaction, may seem unconventional. However, in the domains of art and entertainment, which offer rich experience par excellence, this idea is commonly accepted. Creators of novels, plays, films, and music have always used negative emotions to delight their 


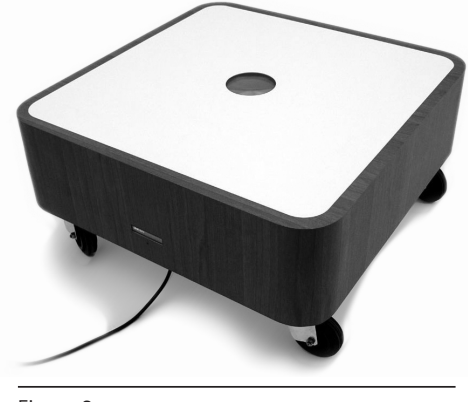

Figure 3

The Drift table. (C) Interaction Research Studio, University of London.
10 Dolf Zillmann, "Mechanisms of Emotional Involvement with Drama," Poetics 23, no. 1-2 (1995): 48.

11 Peter Vorderer and Holger Schramm, "Musik nach Mass. Situative und personenspezifische Unterschiede bei der Selektion von Musik," [Music made to measure. Situational and personal differences in the selection of music], Jahrbuch Musikpsychologie 17 (2004), 89-108; Peter Vorderer, Christoph Klimmt, and Ute Ritterfeld, "Enjoyment: At the Heart of Media Entertainment," Communication Theory 14, no. 4 (2004): 392-93.

12 Dunne and Raby, Design Noir, 58.

13 For an overview of such design approaches, see Pieter M. A. Desmet and Paul Hekkert, "Special Issue Editorial: Design and Emotion," International Journal of Design 3, no. 2 (2009), 1-6. Examples of approaches based on psychological and sociological theory include the following: Jordan (Patrick W. Jordan, Designing Pleasurable Products: An Introduction to the New Human Factors (London: Taylor \& Francis, 2000) used the pleasure framework of Tiger (Lionel Tiger, The Pursuit of Pleasure (New Brunswick, NJ: Transaction Publishers, 1992)) to suggest four sources of product pleasure; Desmet (Pieter M. A. Desmet, "Product Emotion," in Product Experience, ed. Hendrik N. J. Schifferstein and Paul Hekkert (Amsterdam, The Netherlands: Elsevier, 2007) used the appraisal theory of Ortony, Clore, and Collins (Andrew audiences. This intent may be most obvious in the enjoyment of extreme experiences, such as horror movies (anxiety, disgust), shock art (indignation, embarrassment), or rollercoasters (fright), but the effect should not by any means be regarded as a peripheral phenomenon. In fact, any narrative construct-be it written fiction, theatre, or film—contains setbacks and hardship for the protagonists to overcome. A story without any antagonists or dramatic tension is considered "emotionally flat" and will not be very enjoyable..$^{10}$ Similarly, video games can be regarded as a series of obstacles that elicit frustration and aggression in the player, which have to be resolved in succession. Lastly, people enjoy listening to gloomy music that makes them sad, and in fact regularly prefer it over cheerful music. ${ }^{11}$ In other words, negative emotions are a principal part of all these cultural products.

In this paper, we focus on the questions of whether and how the experience of mainstream consumer products-like chairs, smartphones, and copy machines-can also be enriched with negative emotions. The three examples already described are interesting, but they are not intended to become mainstream products; they are part of "critical design," as Dunne and Raby termed it. ${ }^{12}$ This "haute couture" type of design mainly aims to comment on the way people use and co-exist with products in our society, in order to inspire other designers in the process. Thus, although critical design offers designers an incentive to create rich experiences for product users, it does not offer an explicit approach to achieve this effect in "non-critical," everyday products. We are especially interested in understanding why, when, and how negative emotions can contribute to richness in everyday product experiences. In contrast, the design and emotion research domain has produced several practical, experience-driven design approaches, mostly based on psychological and sociological theory. ${ }^{13}$ These approaches have supported designers in creating pleasurable product experiences. However, they do not help us in understanding how negative emotions can enrich these experiences: They detail the nuances on the product side of the interaction, but mostly ignore the nuances on the user side-the question of which emotional experiences are actually enjoyable in the specific context of use. As a consequence, designers still rely primarily on the basic assumption that all positive emotions are pleasant, and thus suitable for product experiences, while all negative emotions are unpleasant and thus unsuitable for design.

Clearly, we challenge this assumption and propose that designers can enrich product experiences by explicitly involving negative emotions in the user-product interaction. To explore this proposition, we examine what motivates people to willfully 
Ortony, Gerald L. Clore, and Allan Collins, The Cognitive Structure of Emotions (Cambridge: Cambridge University Press, 1990)) to propose nine sources of product appeal; and Norman (Donald A. Norman, Emotional Design: Why We Love (or Hate) Everyday Things (New York, NY: Basic Civitas Books, 2004)) proposed three layers of pleasurable product experiences on the basis of a neurobiological framework.

14 Although we see subtle differences between the words "enjoyable" and "pleasant" (e.g., enjoyable has a connotation of something actively entertaining, whereas pleasant seems to refer to stimuli that are more passively agreeable to the senses), these terms are used interchangeably throughout this paper for purposes of readability. engage in activities that evoke negative emotions, and the conditions under which these negative emotions are enjoyable. ${ }^{14}$ We first discuss three existing explanations. Although these theories explain why people seek out negative stimuli in some cases, they cannot explain all such cases, nor do they explain why the resulting negative emotions are sometimes pleasurable. We therefore propose an alternative view that consists of two ingredients. The first is that people seek out negative emotions because such emotions transform their perception of and attitude toward a situation. The second is that people can actually enjoy this transformation if they experience it through a protective frame. With these two ingredients in place, we propose a framework of rich experience that explains the conditions under which negative product experiences can be enjoyable. Finally, we explain how this framework can explicate the richness of "critical design" experiences and enable designers to apply this kind of thinking in a systematic way, in mainstream products. In the last section, we discuss some implications of creating rich experiences with negative emotions, as well as some limitations of the framework.

\section{Existing Explanations of Why People Seek Out Negative Emotions}

Psychologists have long debated why people willingly expose themselves to negative emotions, like those experienced in art and entertainment, but also in activities like physical exercise or parachuting. This debate has generated three main explanations: the utilitarian explanation, the aftermath explanation, and the intensity explanation.

The utilitarian viewpoint is probably the most obvious explanation: People engage in activities that evoke negative emotions not because they enjoy them, but because they expect these activities to be beneficial in the long run. For instance, people who have a fear of flying may still board an airplane, in spite of their fear. They suppress their fear because they want to reach their destination as quickly as possible. Similarly, people overcome their reluctance to engage in physical exercise because they hope to become healthier and slimmer. This view enables us to explain why people buy clock radios with shrill alarms: Although the alarm sounds unpleasant, the sensation of distress is the only reliable means to awaken them. However, the important limitation of this view is that it fails to explain activities or experiences that have no other purpose than to entertain. How would someone expect to be better off riding rollercoasters or watching horror movies? 
15 For instance, this line of reasoning can be found in theories of Soloman and Corbit (Richard L. Solomon and John D. Corbit, "An Opponent-Process Theory of Motivation: I. Temporal Dynamics of Affect," Psychological Review 81, no. 2 (1974)) and of Zillman (Dolf Zillmann, "Anatomy of Suspense," in The Entertainment Functions of Television, ed. Percy H. Tannenbaum (Hillsdale, NJ: Lawrence Erlbaum, 1980), 146-50; or in the "Law of Affective Contrast" from Frijda (Nico H. Frijda, The Laws of Emotion (Mahwah, NJ: Lawrence Erlbaum, 2007), 11), which states that "II]oss of misery yields not a sense of normality but positive happiness."

16 Eduardo B. Andrade and Joel B. Cohen, "On the Consumption of Negative Feelings," Journal of Consumer Research 34, no. 3 (2007), 283-300.

17 Marvin Zuckerman, "Sensation Seeking and the Taste for Vicarious Horror," in Horror Films: Current Research on Audience Preferences and Reactions, ed. J. B. Weaver and R. C. Tamborini (Mahwah, NJ: Lawrence Erlbaum, 1996), 157-59.

18 Andrade and Cohen, "On the Consumption of Negative Feelings," 285

19 Ibid., 292
The aftermath explanation proposes that negative emotions in experiences are taken for granted because they make the ensuing positive emotions more enjoyable. For instance, it proposes that a parachute jumper only enjoys the moment after the jump, because it compares pleasantly to the fear she experienced before jumping and while in the air. ${ }^{15}$ This logic also can explain why we willfully spend our Sunday afternoon mowing the lawn: The mowing itself is not what we enjoy, but the satisfaction of having the job done. In fact, the taller the grass, the more tedious and thus satisfying the job will be. Although plausible, this view also has limited explanatory power. Parachutists and horror movie viewers do not seem happy only when the activity is over; they also express enjoyment in the activity itself. This observation is supported by the experiments of Andrade and Cohen, who measured the amount of positive and negative affect in people before, during, and after watching a horror movie. ${ }^{16}$ The results showed that fans of horror movies experience negative emotions throughout the movie, together with positive emotions. Furthermore, Andrade and Cohen detected no aftermath effect in this group; they showed neither a decrease in negative emotions, nor an increase in positive emotions directly after the movie.

The intensity explanation, put forward by Zuckerman, states that certain people are able to enjoy activities like parachuting because they can successfully inhibit the accompanying fear. ${ }^{17}$ To these so-called sensation seekers, the activity is not really frightening anymore-just pleasantly arousing. This effect explains why some people are interested in products like racing bikes: They have learned to ignore the dangers that would deter other people from using them. The same mechanism is proposed to play a role in the enjoyment of horror movies: Fans of the genre have learned to inhibit their disgust and anxiety and simply enjoy their arousing effects. Andrade and Cohen point out a flaw in this line of thinking: If people enjoy parachuting only after learning to inhibit their fear, they argue, why do they begin doing it in the first place? ${ }^{18}$ Their experiments show no difference in the amount of fear experienced between fans and non-fans of horror moviesonly that the fans experienced more joy while watching. In fact, Andrade and Cohen observed a positive correlation between the negative and the positive emotions: "[Horror fans,] not only experienced "opposite" affective states at the same time, but the most fearful scenes were clearly perceived to be the most pleasant ones. ${ }^{\prime 19}$ This conclusion is particularly noteworthy for our current investigation because it highlights a key limitation of all three existing explanations: They all start from the false assumption that negative emotions are fundamentally and therefore always, unpleasant. 
20 Douglas Derryberry and Marjorie A. Reed, "Anxiety and Attentional Focusing: Trait, State and Hemispheric Influences," Personality and Individual Differences 25 no. 4 (1998), 745-61.

21 Elizabeth A. Phelps, Sam Ling, and Marisa Carrasco, "Emotion Facilitates Perception and Potentiates the Perceptual Benefits of Attention," Psychological Science 17, no. 4 (2006), 292-99.

22 Jason Tipples, "When Time Stands Still: Fear-Specific Modulation of Temporal Bias Due to Threat," Emotion 11, no. 1 (2011), 74-80.

23 Bethany A. Teachman et al., "A New Mode of Fear Expression: Perceptual Bias in Height Fear," Emotion 8, no. 2 (2008), 296-301.

24 Gordon H. Bower, "Mood and Memory," American Psychologist 36, no. 2 (1981), 129-48.

25 This distinction may seem self-evident, but the common practice in empirical studies for many years was to look at the effects of all negative emotions together, under the umbrella term of "negative affect." A number of researchers have recently started to study the differentiated effects of negative emotions in experiments and found widely diverging results. For a discussion, see Jennifer S. Lerner and Dacher Keltner, "Beyond Valence: Toward a Model of EmotionSpecific Influences on Judgment and Choice," Cognition \& Emotion 14, no. 4 (2000): 474-76.

26 Ibid., 473-93.

27 Simone Schnall et al., "Disgust as Embodied Moral Judgment," Personality and Social Psychology Bulletin 34, no. 8 (2008), 1096-109.

\section{Alternative Explanation of Why People Seek out Negative Emotions}

We propose an alternative explanation that in contrast is based on the assumption that negative emotions can also be enjoyable. The key concept in our explanation is "subjective transformation:" People seek out negative emotions because they produce specific bodily and mental effects, which together transform their perception of, and attitude toward, the situation. This concept of transformation is inspired by Sartre's phenomenological conception of emotions, but it is also grounded in contemporary psychological understanding of emotion. We explain the proposition step-by-step through its four main components: (1) bodily and mental effects of negative emotions, which are (2) emotion-specific, lead to (3) transformations of perception and (4) transformations of attitude.

\section{Bodily and Mental Effects of Negative Emotions}

The idea that emotions have bodily effects is undisputed. For example, fear increases the heart rate, which helps the individual to move and act more quickly in case of danger. Recent research has also uncovered mental effects of different emotions: Negative emotions change people's attention, thoughts, memory, imagination, judgment, needs, and behavior. For example, fear not only increases arousal, it also has been shown to have other effects:

- It gives people a narrower field of attention. ${ }^{20}$

- It improves visual contrast sensitivity. ${ }^{21}$

- It causes people to experience time as passing more slowly.22

- It influences people's ability to estimate sizes of objects and distances. ${ }^{23}$

- It brings back memories of previous dangerous situations. $^{24}$

\section{Emotion-Specific}

Negative emotions have different sets of bodily and mental effects. The effects of sadness, for instance, differ strongly from those of anger. ${ }^{25}$ Several studies have shown that certain negative emotions even have opposing effects. For example, Lerner and Keltner demonstrated that whereas fear caused people to estimate that reallife risks (e.g., natural disasters or brain cancer) are more likely to occur than they are in reality, anger caused them to assess the same risks as less likely to occur than they actually are. ${ }^{26}$ Another study showed that participants who experienced disgust became much sterner in their moral judgments of other people's bad behavior in stories, compared to the neutral control group. Sad participants became slightly less judgmental than the neutral group. ${ }^{27}$ Different 
28 Derek D. Rucker and Richard E. Petty, "Emotion Specificity and Consumer Behavior: Anger, Sadness, and Preference for Activity," Motivation and Emotion 28, no. 1 (2004), 3-21.

29 See, for instance, Richard S. Lazarus, Emotion and Adaptation (New York: Oxford University Press, 1991), 84.

30 Jean-Paul Sartre, Sketch for a Theory of the Emotions, trans. P. Mairet (London: Methuen, 1939/1962), 39-40. negative emotions also can have opposing effects on which activities people prefer: When presented with ads for holiday resorts, sad people (i.e., those who had previously read a magazine article inducing sadness) preferred an ad that highlighted the relaxing nature of a particular resort, while angry people (i.e., those who read a story inducing anger) preferred the ad that promoted the active aspects of the same resort..$^{28}$ These examples illustrate just a few effects of a few specific emotions. A complete overview of all such effects for every emotion does not yet exist, as this area of research is just emerging. Future studies eventually could map the whole range of effects that each emotion produces.

\section{Transformation of Perception}

From a functional point of view, the effects previously discussed can be understood as useful responses that help people to survive..$^{29}$ In case of fear, the narrowed field of attention helps the frightened individual to single out the actual threat from the side issues; the memories of previous dangerous situations help the individual to find a solution for the current predicament; and the experience of time moving more slowly increases the individual's ability to identify and process a solution. However, from a phenomenological point of view, these effects also have a significant effect on a person's subjective experience of the situation. Consider fear again: The sudden focus of attention, the memories of past frights, and the feeling that time is standing still are all significant deviations from neutral, everyday experiences. Moreover, this change is not experienced as a set of separate or sequential effects, but rather as a holistic transformation that makes perceived objects, people, and events take on a different meaning. This view is inspired by Sartre's phenomenological conception of emotion, which he described as magical transformations of the deterministic and factual world into subjective reality. ${ }^{30}$ To grasp how this "magical transformation" can be described, consider the following metaphor of a frightening event. If subjective perception is like a theatre stage, fear would abruptly change the arrangements and stage lighting so that only a few crucial objects or actors are illuminated, in a way that reveals a new side of them in vivid detail. These objects and actors would seem to stand still for a moment, although they are all turned toward the person experiencing the fear because she plays the pivotal role in this arrangement. Other emotions could be described by different arrangements of the same metaphor.

\section{Transformation of Attitude}

These specific changes of attention, expectations, judgments, and preferences also influence a person's attitude toward the situation. The word "attitude" here means one's subjectively experienced disposition toward events, people, and objects (summarized as 
Figure 4

Process of subjective transformation.
31 Nico H. Frijda, The Emotions (Cambridge: Cambridge University Press, 1986), 69-93.

32 Maya Tamir and Brett 0 . Ford, "Choosing to Be Afraid: Preferences for Fear as a Function of Goal Pursuit," Emotion 9, no. 4 (2009): 488-97.

33 For example, he proposed that, apart from the well-known unpleasant anger, "anger" (in quotation marks) can also be "the kind of devilish glee one might experience while being objectionable in some social setting, or the mischievousness one might feel in getting one's own back in some underhand way, or the joyous hate one experiences towards the villain in a cowboy film." See: Michael J. Apter, Reversal Theory: The Dynamics of Motivation, Emotion, and Personality, 2nd ed. (Oxford: Oneworld, 2007), 119.

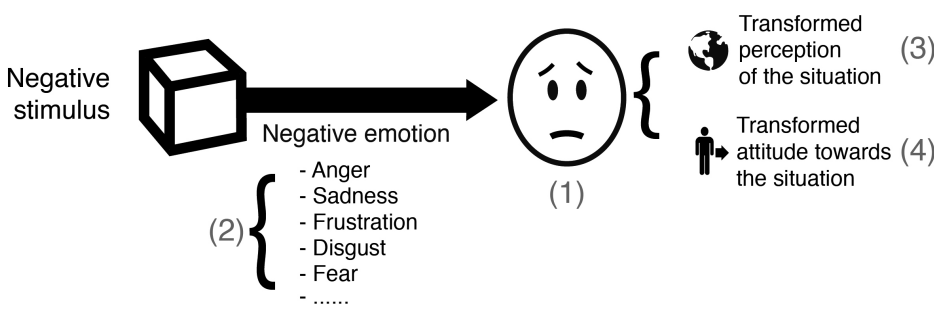

"the world"). For instance, a person who becomes angry has an increasingly assertive, empowered, and risk-taking attitude toward the world. Sadness, on the other hand, results in a more calm, sensitive, and reflective attitude toward the world. This idea of transformed attitudes is similar to Frijda's concept of the action tendency, which is people's tendency to behave in a certain way under the influence of an emotion. ${ }^{31}$ The difference between attitude and action tendency is that the latter is a behavioral concept, described with objective terms such as "approach," "avoidance," "inhibition," and "activation." Attitude, on the other hand, refers primarily to individuals' subjective account of their disposition to the world, and transformations of attitude are first and foremost felt changes. Tamir and Ford used action tendency to explain why people performed better in certain games when emotions were induced beforehand that corresponded to the type of game. ${ }^{32}$ For instance, angry people performed better in a confrontational game, while frightened people performed better in a threat-avoidance game. This improvement in performance did not occur when participants had a non-corresponding or neutral emotion before the game.

To summarize, we propose that every negative emotion has a different combination of bodily and mental effects, which holistically generate a unique transformation of subjective perception and attitude (see Figure 4). In our view, this transformation is what makes the negative emotion potentially refreshing, enchanting, empowering, exciting, or profound-and thus worth experiencing. The transformation is either a welcome change from the status quo-for an agreeable person to get angry once in a while is refreshing-or the right attitude at the right moment can help deal with a situation-someone who has to undergo an intimidating job interview feels more assertive and focused if she is a little angry.

\section{The Enjoyment Condition}

The question remains as to whether negative emotions can also be pleasant, and if so, under which circumstances. For instance, when someone with a fear of heights looks down from a tall building, he might also have a lively experience and a highly focused and energized attitude, but he is not necessarily enjoying himself.

Michael Apter was one of the first authors in psychology to theorize that negative emotions have pleasant counterparts, which he called "parapathic emotions." ${ }^{33}$ Apter proposed that one of the 


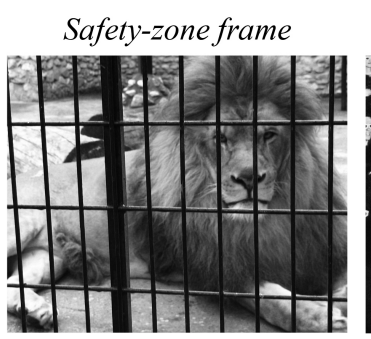

Figure 5

The four types of pretective frame.
34 For instance, if the lion is in an enclosure that is imperceptible, a person standing next to it will not be enjoying the situation, even if she is actually safe.

35 Apter, Reversal Theory, 50-53.

36 We revised this terminology because "confidence" is a psychological state that cannot directly be manipulated by design, whereas the amount of control that the user has over a certain interaction is a designable aspect.

37 This example also shows that the feeling of trust is often a necessary aspect in the experience of a safety-zone frame. People can only feel safe from a lion behind a barrier if they can trust the barrier was well-constructed.
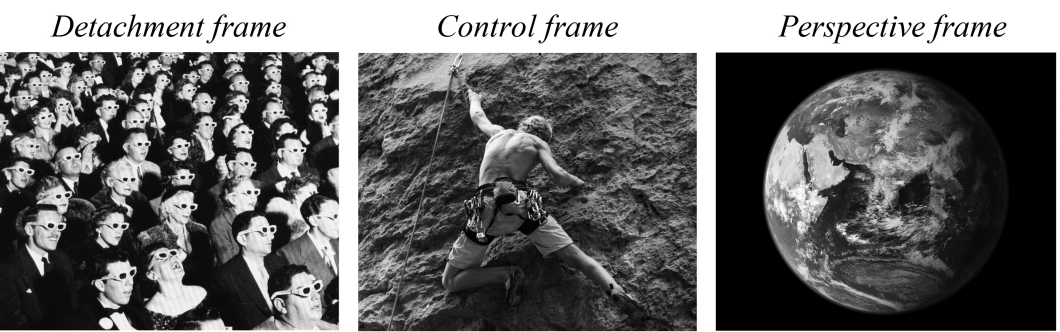

most important factors that causes people to enjoy negative emotion is the presence of a "protective frame." This frame is the mental construct that enables people to create a certain psychological distance between themselves and the object of their emotion. For example, consider an encounter with a hungry lion. If the lion is unrestrained, it will arguably elicit only fear in the unfortunate person encountering it; on the other hand, if the lion is in a cage (but still clearly visible and audible), the encounter can elicit an enjoyable thrill. This example can be used to highlight two important features of the protective frame. First, the protective frame (the cage) converts the negative experience (fear) into an enjoyable experience (thrill), but it does not diminish or take away the negative emotion itself. The fear is necessary for the situation to be enjoyable; a cage without a lion would just be dull. Second, the protective frame is not a physical but a psychological construct, which means that the determining factor is not whether the person is, in reality, safe but whether she believes that she is safe. ${ }^{34}$

Apter originally proposed three different types of protective frames: the detachment frame, the safety-zone frame, and the confidence frame. ${ }^{35}$ After considering how these frames might apply to product design, we recognized that the confidence frame is better termed the "control frame" to make it more suitable for product interaction. ${ }^{36}$ In addition, we added a fourth frame to account for a wider range of applications: the "perspective frame" (see Figure 5). We explain these four protective frames in the following paragraphs.

The safety-zone frame arises when a person perceives a negative stimulus in her direct environment but feels protected from it. The lion in the cage is a typical example; people can enjoy the awe and terror of being close to a lion if they believe they are safe at the same time. ${ }^{37}$ Note that this protecting barrier does not have to be a fixed enclosure. A child who finds a dead bird might be reluctant to touch it with her hands, but poking it with a stick can elicit the right mix of horror and safety. Wearing rubber gloves can provide a similar protective frame. A safety-zone frame can also be achieved through spatial distance. For instance, someone can enjoy the thrill of standing on a cliff as long as he is far enough from the edge. 
Figure 6

The Rich Experience framework.

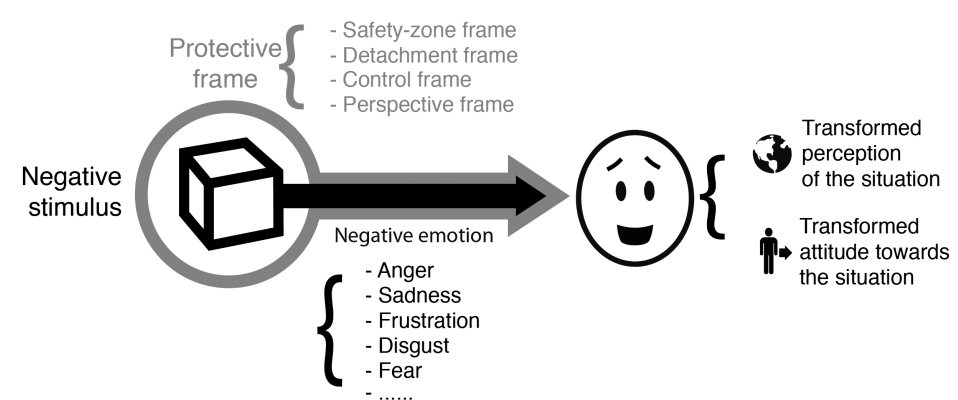

A detachment frame lets people observe an event without participating in it, as occurs in the experience of novels, films, and plays. Through this frame, people are dealing with a representation of a negative stimulus rather than the stimulus itself. For instance, watching a movie scene about a fighting couple might be an entertaining experience, whereas it would be unpleasant to witness in real life. A detachment frame can manifest in different forms, including abstraction (e.g., reading about the number of victims of a disaster rather than seeing photographs of them), simplification (e.g., a line drawing of a wound rather than a photograph), stylization (e.g., a beautiful picture of a collapsed building), and exaggeration (e.g., violence ad absurdum in a slasher film).

With a control frame, people have a certain amount of control over the interaction with the negative stimulus. Although they are actually in the danger zone, they trust they have the skills to keep themselves from trauma. For instance, a first-time driver might feel terrified when driving on the highway, but a skilled driver, who is running comparable risks, is much more at ease. Types of control that people potentially have in a challenging situation include physical skills (e.g., the user is strong/fast/agile enough to deal with the situation) and mental skills (e.g., the user is smart/ knowledgeable/skilled/creative enough to deal with the situation).

The perspective frame changes the meaning of the experienced emotion by providing a window to the wider implications of the situation. This frame connects the negative stimulus to a universal human theme. For example, people who participate in a charity run might experience fatigue and pain, but the realization that they are doing it for a good cause can convert these sensations into feelings of benevolence. Other examples of such universal human themes are loyalty (e.g., "taking one for the team"), selfactualization (e.g., observing one's own progress in mastering a difficult skill), patriotism (e.g., standing in the rain to raise the flag), or diligence (e.g., giving up free time to finish work).

\section{Rich Experience Framework}

With the addition of the protective frame model, the process of subjective transformation (see Figure 4) can be completed to create a "rich experience" framework (see Figure 6). In this framework, 

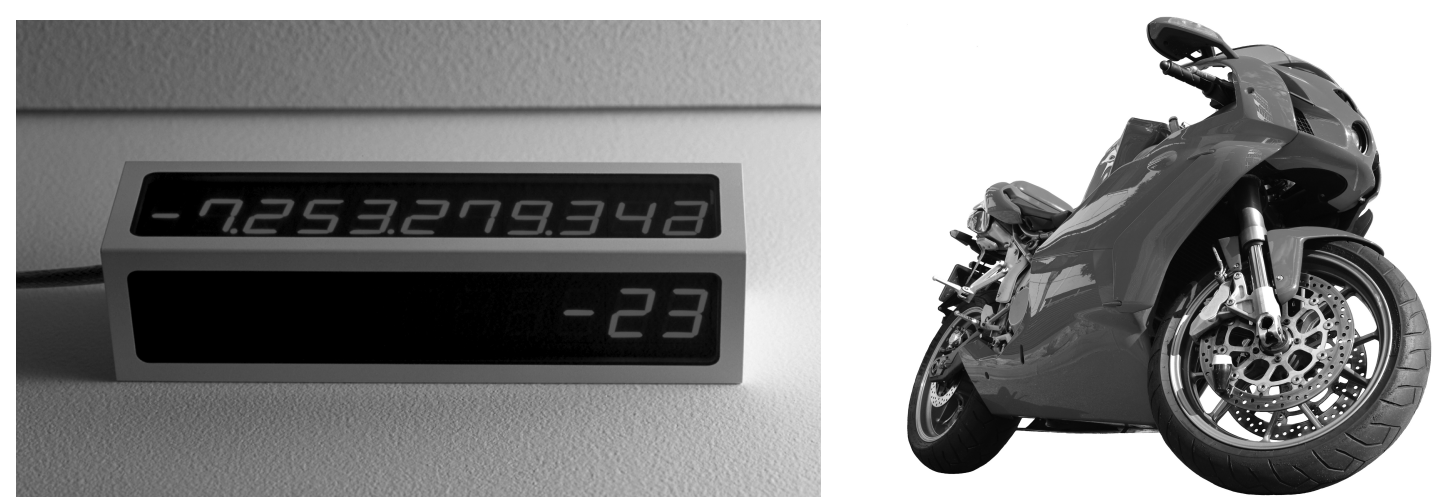

Figure 7 (left)

Life Counter. Photo: Hidetoyo Sasaki.

Figure 8 (right)

Motorcycle.
38 The NHTSA Traffic fact sheet 2008 states: "Per vehicle mile traveled in 2007 , motorcyclists were about 37 times more likely than passenger car occupants to die in a motor vehicle traffic crash and nine times more likely to be injured [in the United States]." http://www-nrd. nhtsa.dot.gov/Pubs/811159.pdf (accessed August 16, 2011). the negative emotion produces the subjective transformation, while the protective frame makes the experience enjoyable. The complete process can be described as follows: Something happens (negative stimulus), which causes a person to have a specific negative emotion (e.g., anger, sadness, etc.). This emotion transforms both that person's perception of the situation, and her attitude toward the situation. Finally, a protective frame around this negative stimulus must manifest in one of four different forms for the person to enjoy the experience.

By distinguishing three components of rich experiences (negative stimulus, protective frame, and subjective transformation), the framework enables us to explain a wide variety of product experiences that are enjoyable while involving negative emotions. Six examples follow that illustrate some of this variety of experience.

\section{Life Counter}

The framework can be used to analyze the previously discussed life counter, which counts back the time its user still has to live (see Figure 7). This product can potentially evoke a mix of horror, anxiety, and sadness, which pulls people out of their everyday flow of thoughts and adds a sense of mystery and contemplation. The main protective frame for this product is the perspective frame: The sad or anxious feelings are accepted because they lead the user to reflect on his or her mortality. Secondarily, the user's choice between different time displays (years, days, hours, and seconds) provides a control frame because the user has control over the type or level of negative emotion experienced. The relatively static display of time-in-years may evoke mild feelings of sadness and resignation, while the display that shows the user's life shorten every second might primarily evoke anxiety or distress.

\section{Motorcycling}

Although all forms of road use come with a certain risk, motorcycling is considered particularly dangerous (see Figure 8). ${ }^{38}$ This fact does not seem to deter people from riding motorcycles. On the contrary, the design and marketing of most motorcycles emphasize 


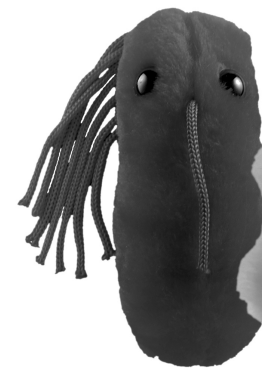

Typhoid

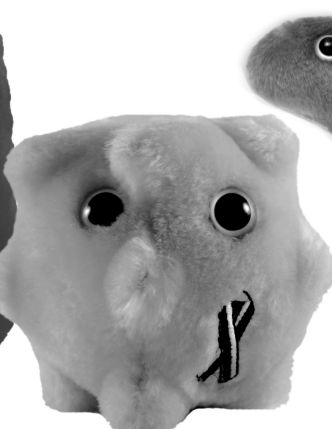

Hepatitis $\odot$

Figure 9 (left)

Giant Microbes. Typhoid, Hepatitis and Cholera Dolls are a property of Giantmicrobes, Inc.

Figure 10 (right) Spicy food.
39 Joshua J. Tewksbury and Gary P. Nabhan, "Seed Dispersal: Directed Deterrence By Capsaicin in Chilies," Nature 412, no. 6845 (2001): 403-04

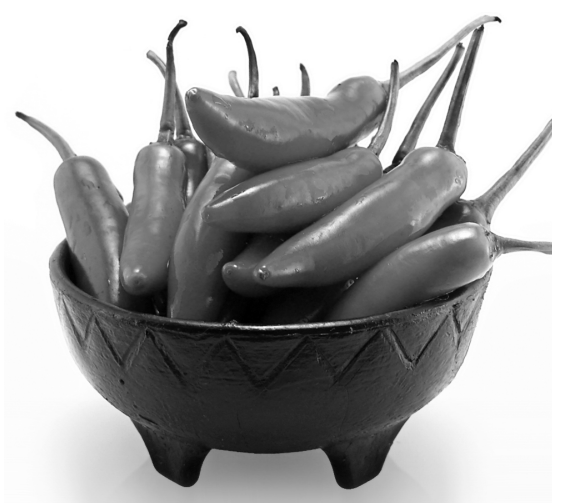

Cholera thrill, power, and speed, rather than safety. The main emotion in these aspects of motorcycle riding is fright. This form of immediate fear is highly stimulating, allowing people to feel that they live in the here and now, as an enjoyable alternative to the everyday tedium or routine. The main protective frame in the enjoyment of riding a motorcycle is the control frame. Motorcyclists need to feel that they are under control of the situation, which is expressed in product characteristics like maneuverability, braking response, and physical feedback. In a second protective frame, safety accessories such as helmets and crash bars provide a safety-zone frame by limiting the consequences of a possible crash.

\section{Giant Microbes}

The company Giantmicrobes, Inc. makes cuddly plush toys that are representations of microbial diseases like cholera, hepatitis, and herpes (see Figure 9). These toys evoke an inherent contradiction of attraction and repulsion, which makes them stand out in a large and saturated market. By evoking disgust, they manage to draw attention and spark children's imagination. In this case, a detachment frame makes the experience enjoyable, as the children are only playing with representations of harmful diseases.

\section{Spicy Foods}

Negative emotions can also be enjoyed on a basic, sensory level, in the experience of pain. Even though the sensation of eating very spicy chilies can be very distressing and uncomfortable (see Figure 10 ), some people enjoy this experience and even try to push the limits of how much pungency they can withstand. This behavior is paradoxical because the pungent substance that is excreted by chili plants is actually meant to prevent mammals from eating them..$^{39}$ Two protective frames play a role in the enjoyment of spicy foods: the control frame and the perspective frame. The control frame is relevant because the person has control over the speed and amount of food intake. The perspective frame comes into play whenever the person eating the spicy food can connect the pain he is enduring to ideas of personal perseverance and resistance. 

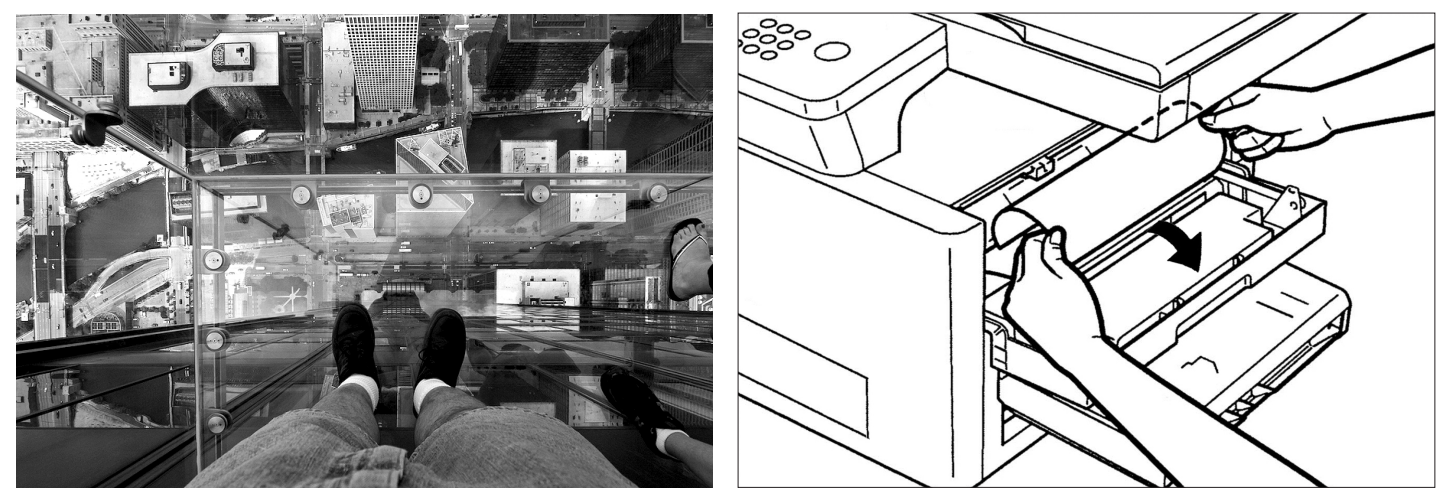

Figure 11 (left)

Glass balcony.

Figure 12 (right)

Printer problems
Glass Balcony

The Willis Tower in Chicago features three glass balconies at the one-hundred-third floor that offer visitors a unique experience (see Figure 11). Part of this experience is the panoramic view of the city, but the more intense anxiety stems from the sensation of standing on "thin air," which certainly adds suspense and novelty. The protective frame is a safety-zone frame. Visitors trust that the people who are responsible for the balcony have ensured the safety of the experience.

\section{Printer Problems}

Sometimes products can provide rich experiences through interactions that are unintentional or even unwanted by the manufacturer. Consider a user who sends a digital document to a printer but discovers that the printer has a paper jam (see Figure 12). The subsequent scavenger hunt to find the stuck piece of paper can evoke frustration. However, if the user is not in a terrible hurry and has an idea about how to resolve this issue, the experience can actually be enjoyable. The frustration has the ability to make the person more determined and focused on resolution, and it adds a sense of accomplishment afterward. The enjoyment condition is a version of the control frame: The user must believe that she still has options to try or steps to follow. When the user feels that she has tried everything and the printer is still unresponsive, the protective frame fails and the enjoyment will cease.

These examples illustrate that different rich experiences involve different constellations of the three key components described in the framework. They also illustrate that the substantial differences in people's experiences of situations that involve negative emotions are explained by the subjective nature of the protective frame. For some people, the thick glass bottom of the Willis Tower's balcony provides a safety-zone frame; for others it does not. The first group is excited, and the second is plain fearful. A mild chili sauce is boring for some and exciting for others. 


\section{Discussion}

We are interested in understanding how design can provide users with rich product experiences-experiences that go beyond onedimensional pleasure. Our ultimate goal is to offer designers tools to compose rich palettes of emotions for their product experiences, drawing from the large set of potentially enjoyable positive and negative emotions. This paper represents a first step by introducing a framework that describes the conditions under which negative emotions are pleasurable. The next steps are to formulate practical design strategies and to extend the framework to enable more fine-grained distinctions. ${ }^{40}$ For example, for design applications, more information must be generated about the specific transformations (of both perception and attitude) of different negative emotions. Because product experiences are, in essence, dynamic, the framework should ideally also include the element of time. ${ }^{41}$ Rich experiences are not just for people with an eccentric taste or for thrill-seekers; just as everyone enjoys some form of art and entertainment, everyone can enjoy rich product experiences. However, exploring cultural and individual differences in the level of engagement and acceptance of rich experience products might also generate valuable insights. For instance, initial indications are that both elderly people and people of eastern descent are more appreciative of mixed emotions, at least for an experience that includes sadness..$^{42}$ In addition, young people may be more inclined to engage in thrilling activities that involve emotions like fear and disgust. Ideally, as more details and the element of time are incorporated, the framework can expand to become a tool that enables designers to create rich experiences in a way that is similar to writing stories: They can carefully plan different emotional narrative elements through time to compose a holistic and meaningful experience.

Rich experience design potentially offers at least three benefits. First, it can add engagement, refreshment, or meaning to situations that are generally boring or void of meaning. Second, it can make use of the specific effects of negative emotions on attitude to stimulate people toward engagement in activities in which they otherwise would not engage. Note that this effect also has a dark side: Products that are designed to make use of protective frames (e.g., cars with many airbags) might induce reckless use or behavior because they provide a sense of safety that overshadows the actual risk. Third, and perhaps most important, it can result in strategies for situations that will always have some negative aspect, including hospital visits, waiting in line, traffic jams, and air travel. For example, consider the printer situation already described. Printer designers most likely do not intend to evoke 
negative emotions. However, even in this case, understanding how to use the concepts of protective frame and transformation offers opportunities: If taking away the negative stimulus is not possible (i.e., occasional paper jams are unavoidable), clever design might help transform this negative stimulus into a rich rather than an unpleasant experience. In fact, in these kinds of situations, trying to add positive emotions is counterproductive because they form a dissonant with the reality of the situation. Instead, it is better to acknowledge that the situation is (partly) negative and to design something that either redirects this negativity or makes it enjoyable.

\section{Acknowledgements}

The authors would like to thank Paul Hekkert for his helpful comments on an earlier draft of the paper.

This research is part of the Creative Industry Scientific Program (CRISP), which focuses on the design of product-service systems as a means to stimulate the continuing growth of the Dutch Design Sector and Creative Industries. The CRISP program is partially sponsored by the Dutch Ministry of Education, Culture, and Science.

This research was supported by MAGW VIDI grant number 452-10-011 of The Netherlands Organization for Scientific Research (NWO), awarded to P. M. A. Desmet. 